Kula Lucja, Kalinowska Julita, Koczor-Rozmus Aleksandra. Endodontic treatment regimens and their application in practice survey and comparative study. Journal of Education, Health and Sport. 2021;11(7):30-43. eISSN 2391-8306. DOI http://dx.doi.org/10.12775/JEHS.2021.11.07.003

https://apcz.umk.pl/czasopisma/index.php/JEHS/article/view/JEHS.2021.11.07.003 https://zenodo.org/record/5076337

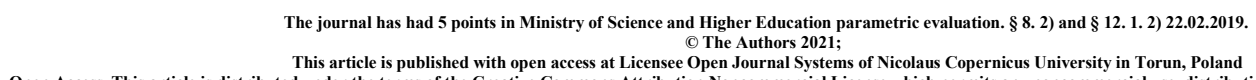

Open Access. This article is distributed under the terms of the Creative Commons Attribution Noncommercial License which permits any noncommercial use, distribution, and reproduction in any medium, provided the original author $(\mathrm{s})$ and source are credited. This is an open access article licensed under the terms of the Creative Commons Attribution Non commercial license Share alike.
(http://creativecommons.org/licenses/by-nc-sa/4.0/) which permits unrestricted, non congercial The authors declare that there is no conflict of interests regarding the publication of this paper.

Received: 07.06.2021. Revised: 16.06.2021. Accepted: 06.07.2021.

\title{
Endodontic treatment regimens and their application in practice - survey and comparative study
}

\author{
Lucja Kula ${ }^{1}$, Julita Kalinowska ${ }^{1}$, Aleksandra Koczor-Rozmus ${ }^{2}$
}

${ }^{1}$ Student's Scientfic Society of the Department of Conservative Dentistry with Endodontics, Medical University of Silesia, Faculty of Medical Sciences, Pl. Akademicki 17, 41-902 Bytom, Poland

${ }^{2}$ Department of Conservative Dentistry with Endodontics, Faculty of Medical Science, Medical University of Silesia, Pl. Akademicki 17, 41-902 Bytom, Poland *Correspondance: akoczor@sum.edu.pl, Phone.: +48602247826

Julita Kalinowska https://orcid.org/0000-0003-1579-8310 Phone: +48506-624-601 julita.kalinowska@gmail.com Łucja Kula https://orcid.org/0000-0001-9636-843X Phone: +48662-184-112 lucja.kula@outlook.com Aleksandra Koczor-Rozmus https://orcid.org/0000-0002-1300-2991, Phone: +48602247826 


\begin{abstract}
Introduction: Endodontics is a rapidly developing field of dentistry. Dentists have an increasing selection of techniques, tools and materials to ensure therapeutic success.

Aim: The aim of study was to analyzed the endodontic treatment regimens and their application in daily practice of dentist.

Material and Methods: A dentist survey was conducted through a Google Doc. The link to the form was placed on online dental groups, sent by e-mail to the offices and the questionnaire was also delivered to the dental offices in a printed form.

Results: The majority of respondents always perform endodontic treatment procedures on pregnant women, take three X-rays and use a rubber dam during the treatment. Almost all respondents have the opportunity to take an X-ray in the workplace, and the working length is usually measured by the electronic method. The most commonly used methods of root canal preparation are the traditional and crown-down methods, and the most commonly used root canal filling method - the thermal method. Most of the respondents declared the following rinsing protocol: $\mathrm{NaOCl}$ and $\mathrm{CA}$ or EDTA. Apex locator, ultrasounds and microscopes are used in most dental offices, and more than half of the dentists responded that they perform procedures like broken tools removal or obliterated canals enlargment. .

Conclusions: Polish endodontics has developed over the years. Modern solutions are used more and more often. The canals are filled with the thermal method, and the popularity of performing complex endodontic procedures has increased. However, it is necessary to conduct further studies comparing the effectiveness of the canal preparation methods and the standardization of the root canal irrigation protocol.
\end{abstract}

\title{
Key words: endodontics; root canal therapy, survey
}

\section{Introduction:}

Endodontics is a field of dentistry that deals with pulp-dentin complex. Treatment consists of correct diagnosis, followed by the removal of the diseased pulp and the elimination of microorganisms through chemo-mechanical preparation of the root canal system. At the end, the tooth is tightly filled and rebuilt. In recent years, there has been a rapid development in the field of endodontics. Dentists have an increasing selection of techniques, tools, materials which apart from skills are an important components in achieving the final therapeutic success [1].

In 2006, The European Society of Endodontology published guidelines, which were to standardize the treatment process and ensure its greatest effectiveness. Unfortunately, the research carried out by Olczak and Pawlicka in 2008 [2] showed large deficiencies and insubordination of Polish dentists - rubber dam used by only $15 \%$ of respondents, continuing popularity of traditional method, which is impossible to achieve the recommended conical shape of the canal [1] or the X-ray equipment available only in the middle of the dental offices. 
Nowadays, most dentists try to keep up with newer methods and tools. Dental office that wants follow the guidelines of the ESE [1], as well as current, commonly available publications on endodontics, should have an X-ray equipment in the workplace, which significantly improves the efficiency of endodontic treatment, because radiographic images taken before, during and after treatment increase the probability of achieving endodontic success [3]. In such dental offices also rubber dam, microscope or ultrasound tools should become an inseparable element of the office. Radiological measurement - often burdened with errors due to the different location of the apical foramen [4] - should be replaced by electronic measurement. The thermal methods, which is characterized by the greatest tightness [5], should replace cold lateral condensation of cold gutta-percha techniques, and hand tools ensuring a slightly greater effectiveness in the elimination of microorganisms [6] should be successively replaced by rotary instruments. The main concern is the variety of rinsing protocol, which has not been standardized in the ESE guidelines. According to the recommendations of the Research Department of the Polish Endodontic Society [7] rinsing protocol should be based on citric acid $(40 \%)$ and sodium hypochlorite $(5,25)$ terminated with $2 \%$ chlorhexidine; K. Olczak [8] suggests the initial use of $\mathrm{NaOCl}$ with ultrasound, which would be combined with EDTA or citric acid, and the entire rinsing would be ended with alcohol or saline. Other sources indicate that the most effective sequence in terms of removing the smear layer is the alternating use of sodium hypochlorite and citric acid [9]. Also, despite clear guidelines published in 2006, a lot of controversy arises about the choice of the most effective method of root canal preparation.

After 13 years, does Polish endodontics finally meet the guidelines laid down by the European Society of Endodontology?

Is the modernity of the methods only a slogan or finally a reality?

Currently, 16 years have passed since the European Society of Endodontology introduced the principles of root canal treatment [1], and 13 years have passed since they were first confronted with reality in the article by Katarzyna Olczak and Halina Pawlicka [2]. Today, it is once again time to compare endodontic regimens with their application in practice.

\section{Aim:}

The purpose of this study was to collect and analyze data on endodontic treatment regimens and their use in dental practice.

\section{Material and methods:}

A survey was administered to 111 dentists who were asked to answer 20 questions. The survey was conducted online via a Google document and was available for almost 2 months. A link to the survey was made available on online groups for dentists and more than 150 emails were sent requesting completion of the survey. In addition, the printed form was delivered to dental practices. The worksheet contains two sections, the first relating to the demographics and biographies of the practitioners (1-4), and the second relating to the methods, tools, and resources used in endodontic treatment (5-20).

The questions in the survey were single and multiple choice; in addition, question number 17 was an open-ended question. The time for answering the questions was unlimited. 


\section{Results:}

The largest group among the respondents consisted of dentists practicing for 1-5 years (43.2\%), a smaller group (27.9\%) consisted of dentists practicing for 11-20 years, 18.9\% were dentists practicing for 6-10 years, and the smallest group consisted of dentists practicing for over 20 years $(9.9 \%)$. The vast majority of the respondents $(92.8 \%)$ did not have a specialty in conservative dentistry with endodontics. The survey showed that more than $90 \%$ of the dentists $(94.6 \%)$ work in a large or medium-sized city, $3.6 \%$ in a small city and $1.8 \%$ in a rural area (up to one thousand inhabitants). It was also found that $69.4 \%$ of the respondents work in private practices, while $30.6 \%$ have a combined practice (see table 1 ).

\begin{tabular}{|c|c|c|}
\hline Question & Response & Year 2021 [\%] \\
\hline \multirow{4}{*}{ Years of practice } & $1-5$ years & 43.2 \\
\hline & $6-10$ years & 18.9 \\
\hline & $11-20$ years & 27.9 \\
\hline & Over 20 years & 9.9 \\
\hline \multirow{2}{*}{$\begin{array}{l}\text { Holding a degree of } \\
\text { specialization }\end{array}$} & $\begin{array}{l}\text { Number of respondents with } \\
\text { specialization }\end{array}$ & 7.2 \\
\hline & $\begin{array}{l}\text { Number of respondents without } \\
\text { specialization }\end{array}$ & 92.8 \\
\hline \multirow{3}{*}{ Workplace } & Big city - over 20.000 residents & 94.6 \\
\hline & Small city - under 20.000 residents & 3.6 \\
\hline & Countryside - under 1.000 residents & 1.8 \\
\hline \multirow{3}{*}{$\begin{array}{l}\text { How the dentist's } \\
\text { office operates }\end{array}$} & NFZ & - \\
\hline & Private & 69.4 \\
\hline & Combined activity & 30.6 \\
\hline
\end{tabular}

Table 1. Summary of responses about demographics and biographies of respondents. 
The possibility of taking X-rays at work was stated by $98.2 \%$ of the respondents. It was also found that $71.2 \%$ of the respondents take three pictures in the course of treatment before, during and after; $26.1 \%$ take two pictures - before and after, and $2.7 \%$ of the respondents take two pictures before and during treatment (see Figure 1-2).

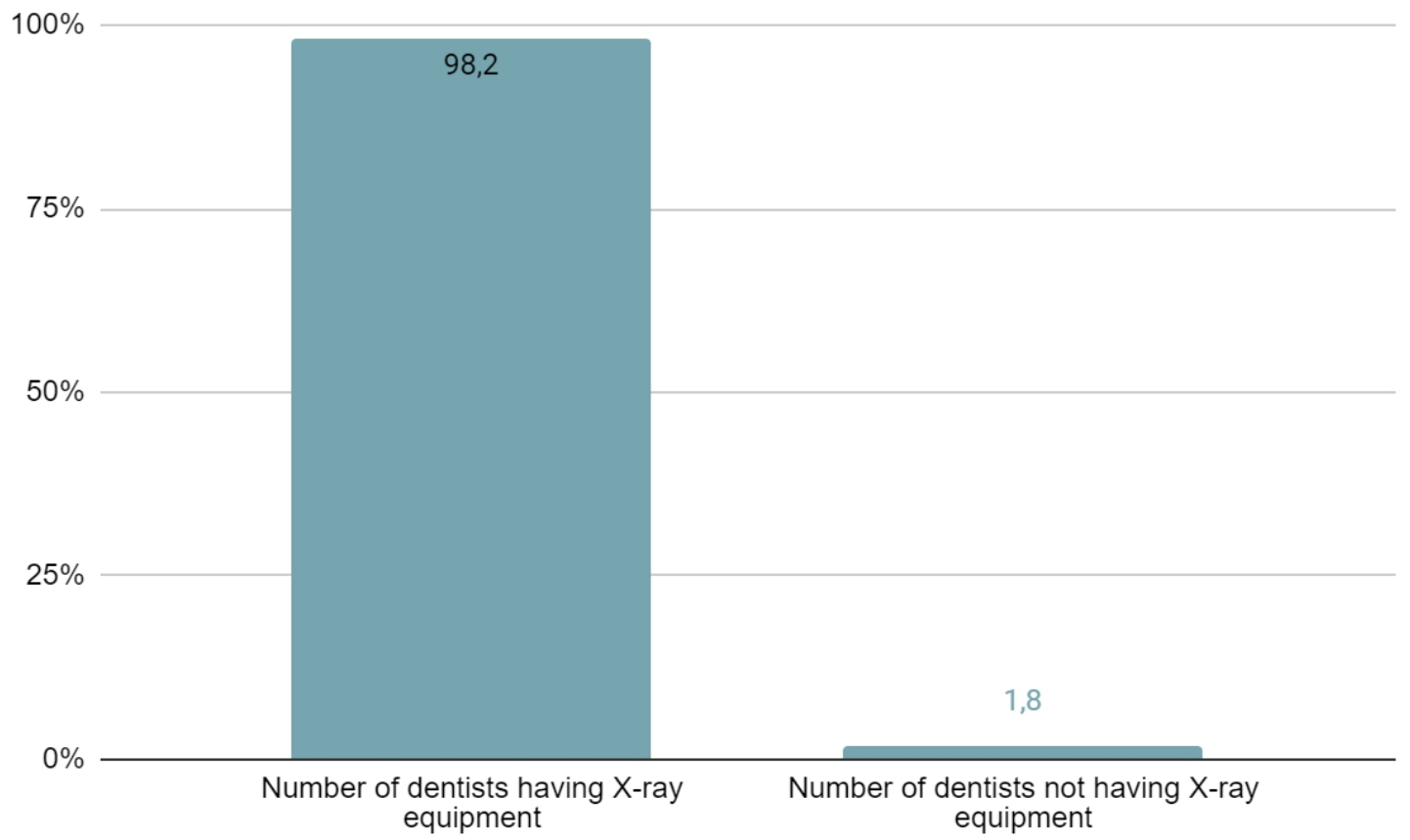

Figure 1. Number of dentists having X-ray equipment.

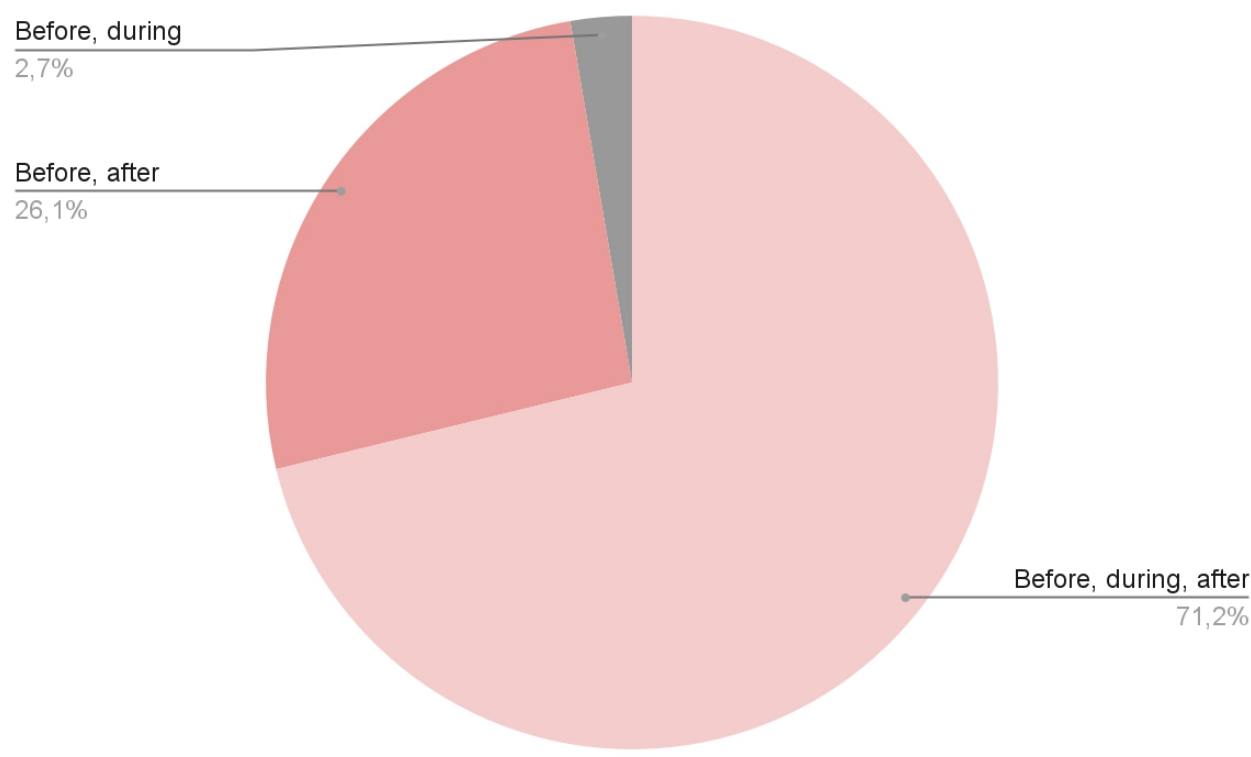

Figure 2. Number of X-rays taken during treatment. 
When asked about the use of rubber dam during endodontic treatment, $79.3 \%$ of the survey participants answered affirmatively (see Figure 3).

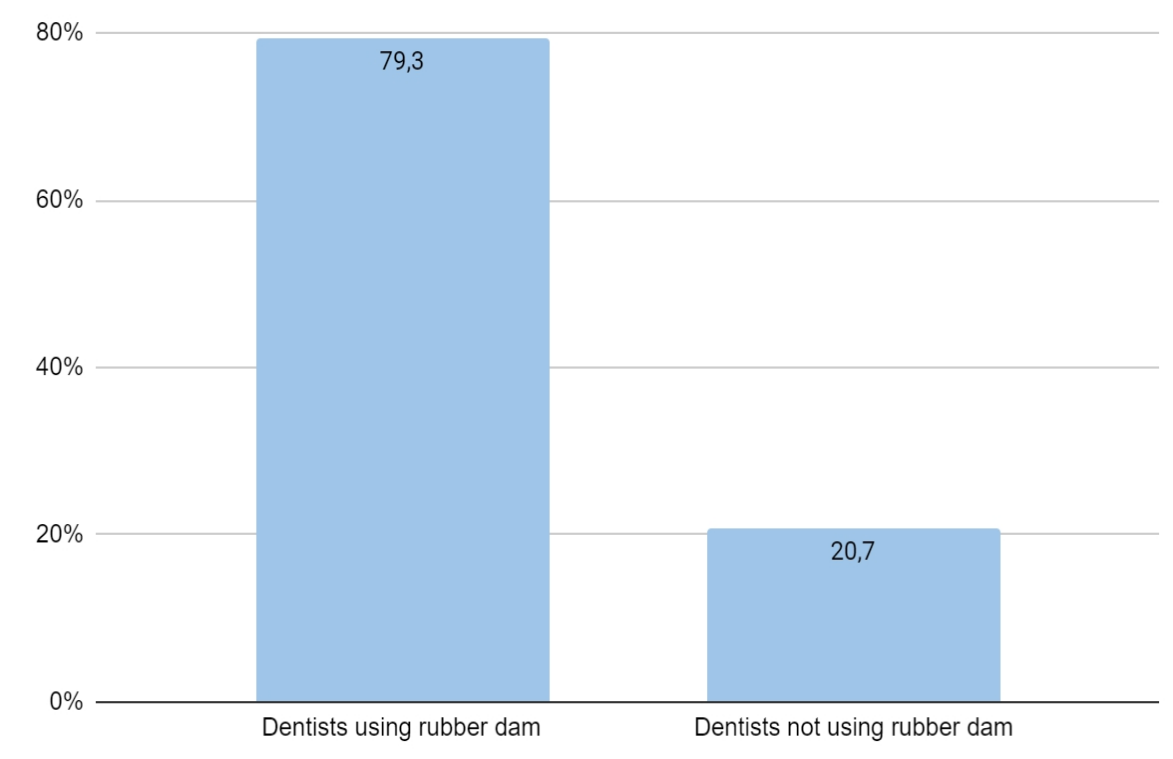

Figure 3. Use of rubber dam.

The most commonly used techniques for root canal preparation were the traditional technique (39.5\%) and the crown down technique (38.8\%). Of the dentists surveyed, $78.4 \%$ prefer to work with rotary systems and only $21.6 \%$ with hand tools. Root canals are filled in $61.3 \%$ by thermal method and $26.1 \%$ by lateral condensation of gutta-percha. Of the sealers, resin-based sealer proved to be the most popular $(87.4 \%)$, followed by the ones with therapeutic substances (10.8\%) (see Figure 4-6). 
$80 \%$

$60 \%$

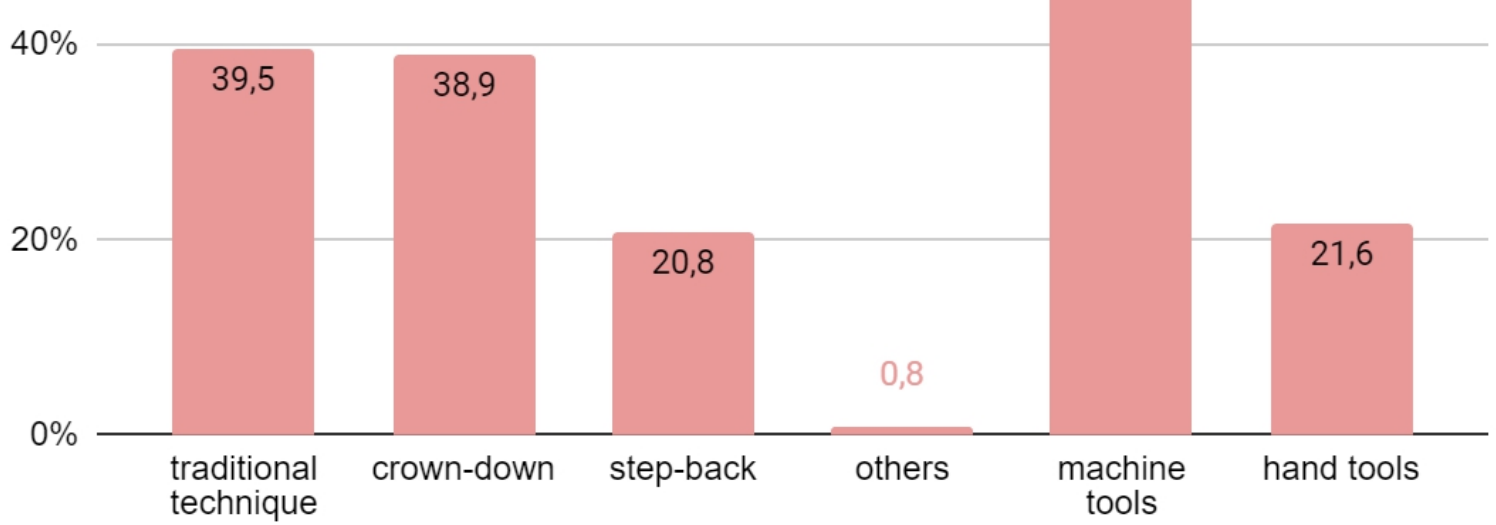

Figure 4. Root canal preparation techniques.

$80 \%$

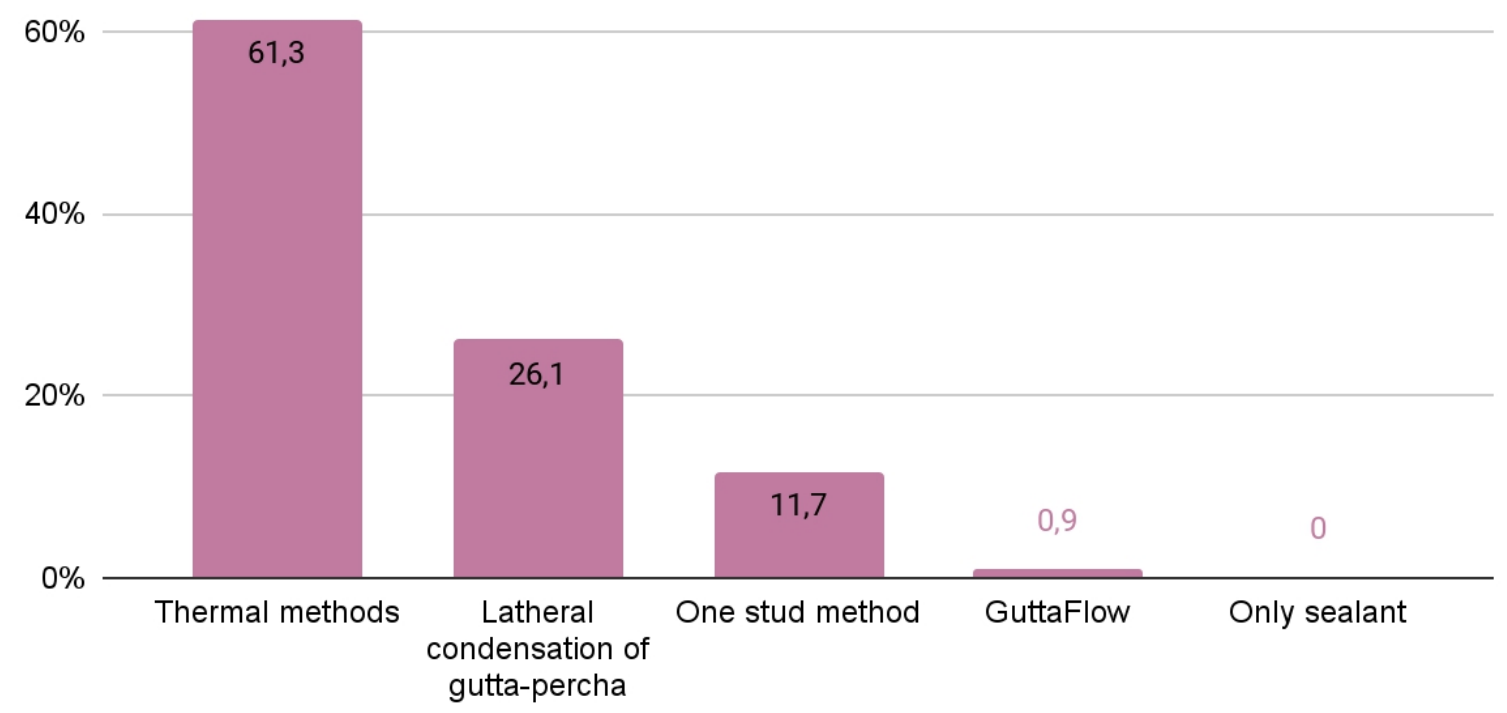

Figure 5. Root canal filling methods.

Figure 6. Use of sealants.

The rinsing protocol included sodium hypochlorite (95.5\%), citric acid (65.77\%), saline $(27.93 \%)$, chlorhexidine $(20.72 \%)$ in various concentrations. With less frequency EDTA $(18.02 \%)$, distilled water $(6.31 \%)$ and isopropyl alcohol $(5.41 \%)$. The respondents who did not respond constituted 4.5\% (see Figure 7-8). 


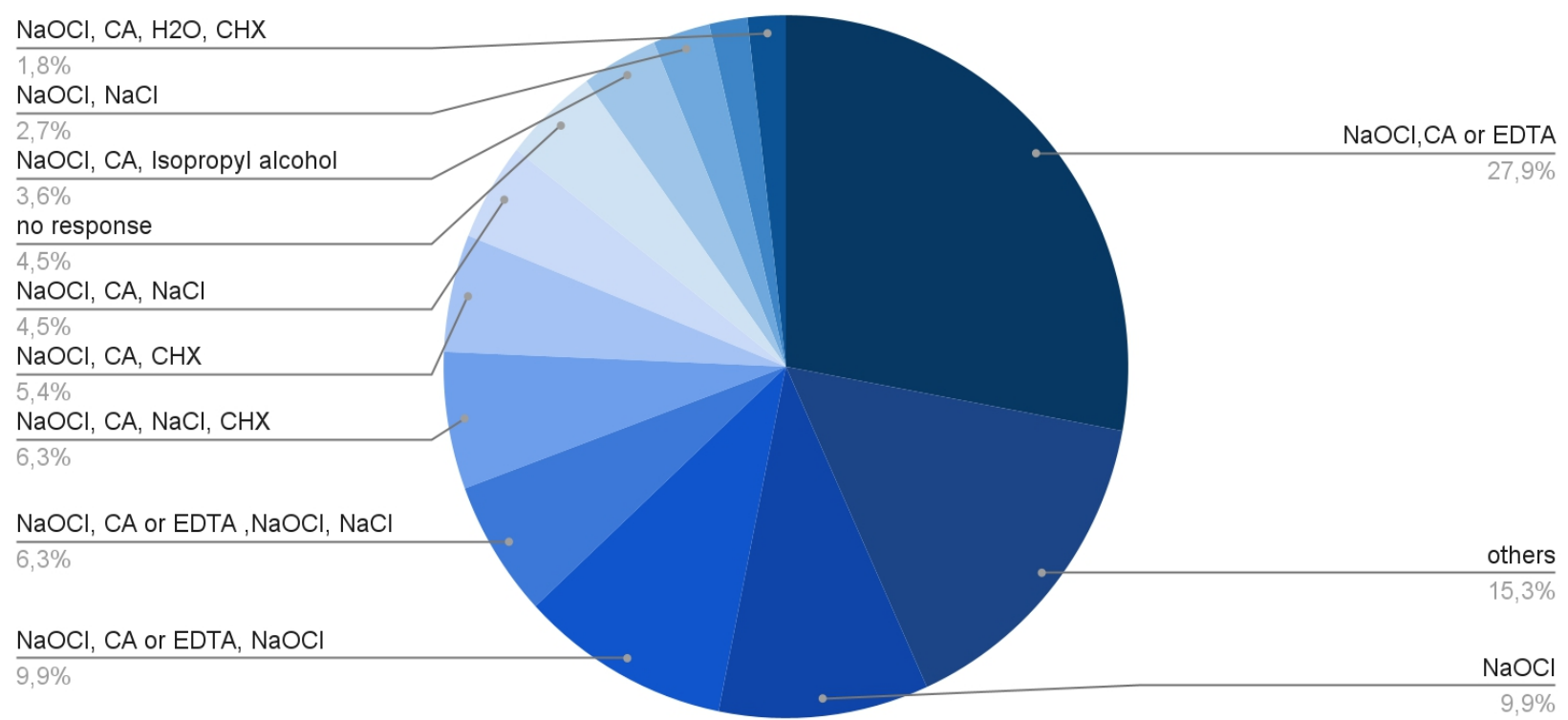

Figure 7. Summary of root canal rinsing protocols.

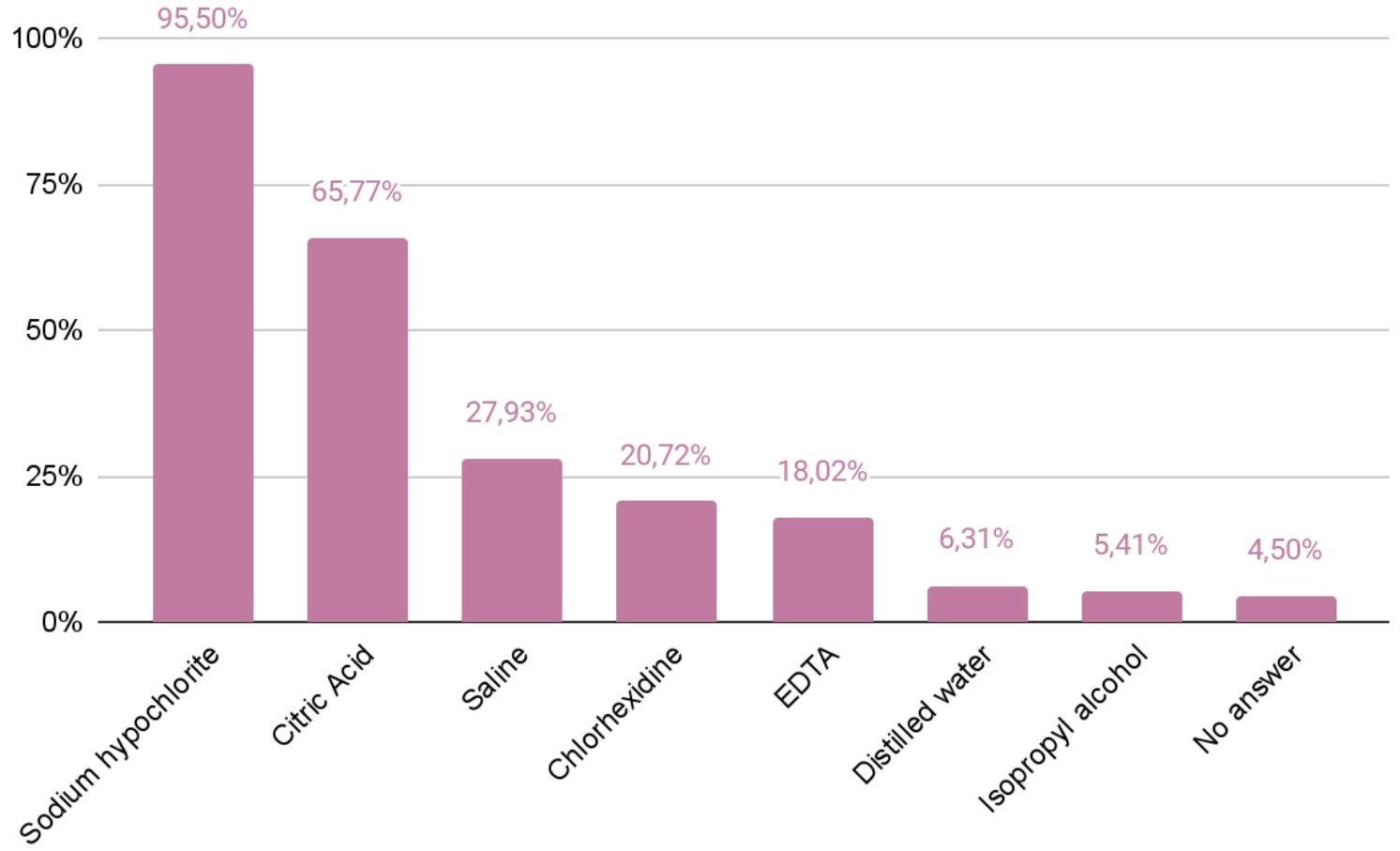

Figure 8. Frequency of rinsing agents.

The survey revealed that apex locator is used by $99.1 \%$ of the respondents, ultrasound is used by $84.7 \%$ of the respondents, microscope is used by $68.5 \%$ of the respondents and dental magnifiers are used in practice by $35.1 \%$ of the survey participants.

The survey revealed that re-treatment of root canals is undertaken by $87.4 \%$ of the respondents, treatment of traumatized teeth by $76.6 \%$, decalcification of the canals by $64 \%$, removal of broken instruments by $51.4 \%$, while only $17.1 \%$ of the dentists said they undertake apicectomy (see Figure 9-10). 


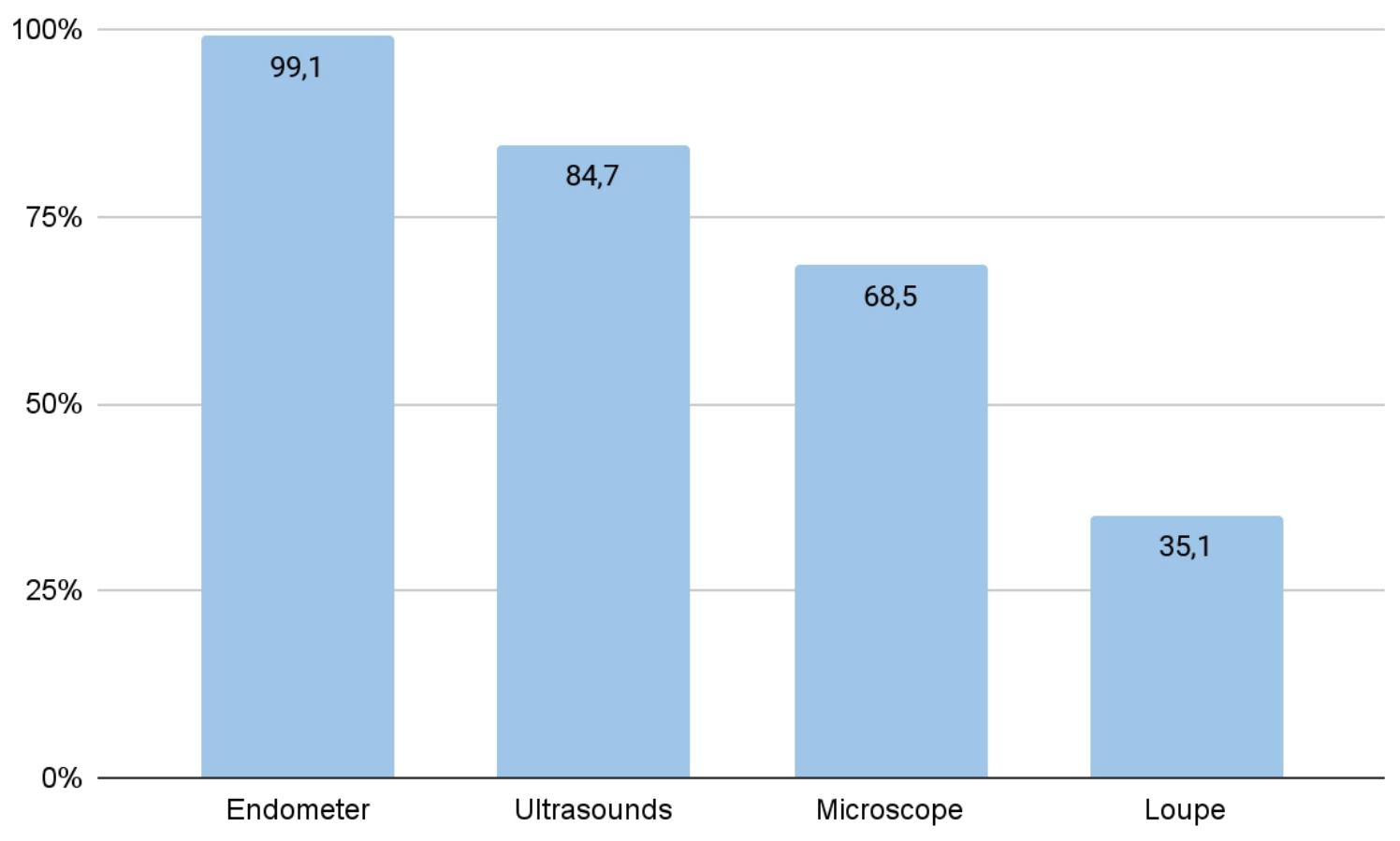

Figure 9. Use of equipment in dental offices in 2021.

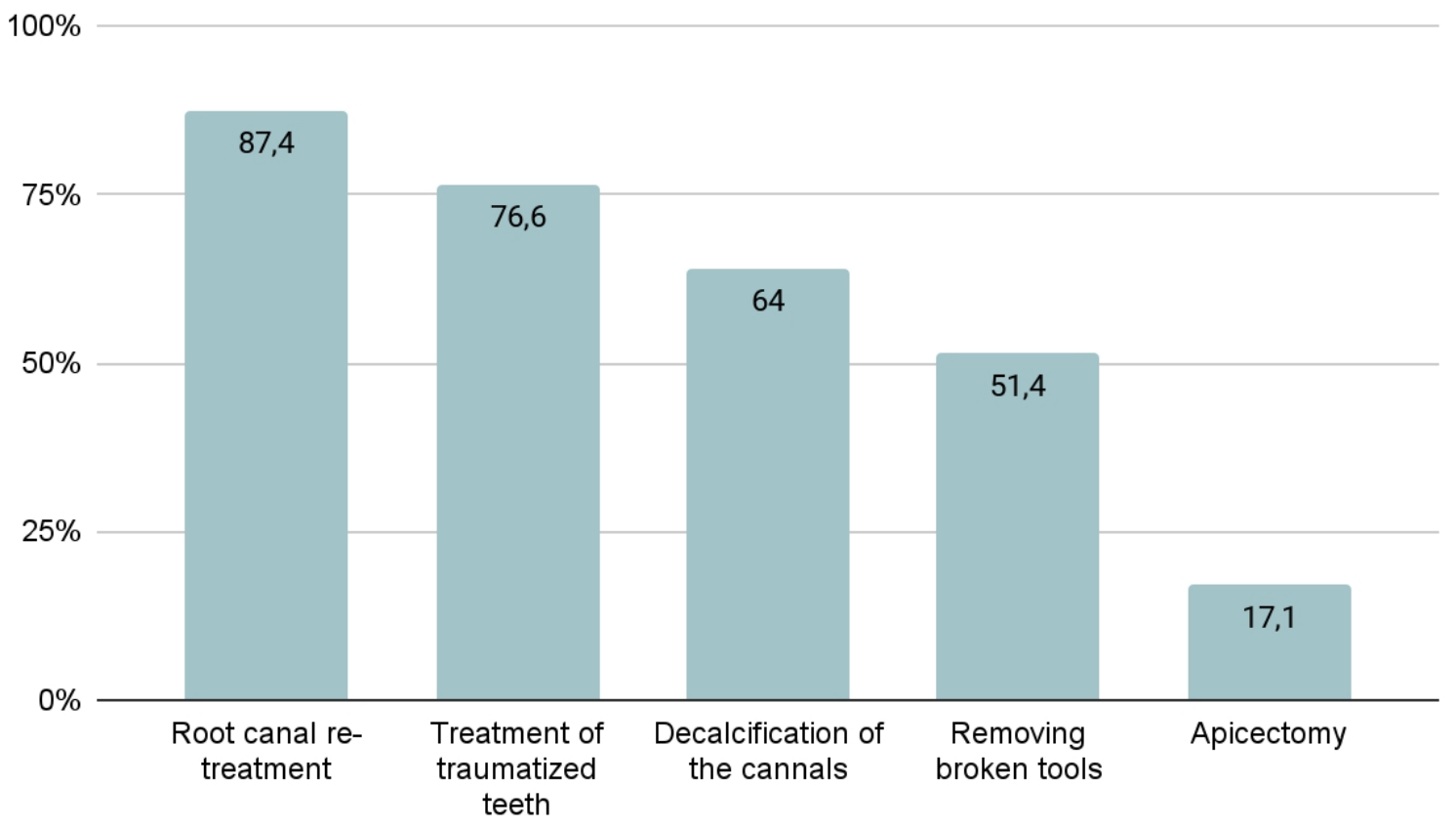

Figure 10. Procedures performed in the dental offices.

The preferred sources of knowledge in endodontics are courses $(88.3 \%)$, internet $(85.6 \%)$ and less frequently books (73\%). Most of the dentists $(73.9 \%)$ declared that they always undertake endodontic treatment of pregnant women, a smaller group - $21.6 \%$ undertake such treatment only in the second and third trimester, and $4.5 \%$ of the respondents never undertake endodontic treatment of pregnant women. 
During endodontic treatment $95.5 \%$ of dentists perform the chemical rinsing process from IAF tool application, while $4.5 \%$ of the respondents start chemical rinsing from MAF tool size. The survey also confirmed that most of the dentists $(93.7 \%)$ restore the cavity wall before endodontic treatment if necessary.

\section{Discussion:}

Dentistry is a field of science that develops on many levels. Endodontics is a demanding specialization - it requires not only a proper preparation and canal filling technique but also compatible materials and tools for each stage of treatment in order to achieve success and patient's satisfaction [10].

Data collected in 2021 showed a significant increase in the ability to perform radiographs in their own office compared to the results collected in 2008 [2], which showed that only $47,8 \%$ had such ability. This is certainly reassuring, because radiographs are an important part of dental care, and as they become more widely available, they facilitate diagnosis, which speeds up the treatment process.

The American Dental Association mentions the following advantages of X-rays [11]: detection of changes invisible to the naked eye, such as carious lesions (e.g. under fillings, in bones, neoplastic lesions), assessment of the proper development and eruption of permanent teeth, including wisdom teeth, assessment of progress in treatment, e.g. during endodontic treatment, assessment of the progress of healing the possibility of planning treatment, e.g. surgical or endodontic treatment

The European Endodontic Society recommends measuring the working length with both radiological and electronic methods. Moreover, according to the ESE recommendations, the electronic method should be confirmed radiographically [1]. Studies have shown that apex locators give more reliable results than the radiological method, which is based on determining the position of the physiological foramen in relation to the root apex. This apex is highly variable depending on the type of tooth and the patient's age - it may even be located laterally to the top of the root [5]. Moreover, apex locators are characterized by over $80 \%$ efficiency in localizing periapical stenosis, whereas radiologically it was possible in only $1 / 3$ of cases. On the other hand, other studies have shown an almost $40 \%$ inaccuracy of measurements by X-ray [5]. Perhaps this is the reason why $99 \%$ of respondents chose the apex locators as the only method of measuring working length.

According to the guidelines of the European Society of Endodontology published in 2006, "root canal treatment should only be performed if the tooth is isolated with a rubber dam" [1]. So it is optimistic that the number of dentists using rubber dam has increased from $14,5 \%$ [2] to $79,3 \%$. Although, according to a 2015 study, "the use of a rubber dam or its absence did not affect the effectiveness of root canal disinfection" [12], there are undoubtedly many benefits of using a rubber dam: [13]. It improves visibility of the surgical field, as the rubber dam retracts the cheeks and lips, reduces the risk of aspiration of tools, e.g. a file or contaminants by the patient, protects the patient and the physician from surgical infection ensures a clean and dry surgical field, free from saliva, blood and surgical residues, and improves bonding strength when using filling materials and cements reduces aerosol sprays in the oral cavity. 
Considering few disadvantages such as difficult contact with the patient or possible discomfort of the patient [13] - rubber dam is a useful element in endodontic treatment.

Among the many root canal preparation techniques, the traditional and crown-down methods were the most frequently chosen. Survey study published in 2008 [2] showed that the most popular techniques were traditional technique (45,5\%), step back technique $(29,4 \%)$ and crown down technique (20\%) [2]. Comparing the results of our survey with the data collected in 2008 [2], we can observe a clear decrease in the popularity of the step-back technique in favor of the crown-down method. Undoubtedly, the continuing popularity of the traditional method for 13 years is also surprising. The European Society of Endodontology recommends cone shaped preparation of the apical part of the root canal, while preserving the natural curvature of the canal [1]. The use of the traditional method is associated with an increased risk of perforation, distortion of the natural curve of the root canal and pushing the canal contents through the apical foramen. Moreover, it leads to excessive preparation of the apical part of the canal, with little preparation of the coronal part. To minimize this risk, other methods, such as step-back and crown-down, are recommended. The crown-down technique additionally allows easier access to the apical part of root canal and, by removing the main mass of infected tissue at the beginning of the canal preparation, reduces the risk of pushing the canal contents through the apical foramen (in comparison with the step-back method).

Almost $80 \%$ of respondents are inclined to use machine tools in their daily work. Undoubtedly, they have many advantages: [14] for example: elimination of the occurrence of pressure increase in the canal by using the crown-down technique, the shape of the tools enables the movement of filings towards the chamber. Working with rotary instruments does not completely exclude manual tools, as they are still used for initial canal preparation, determining working length or for final smoothing of the canal walls. It should also be remembered that machine systems cannot be used in case of canal bifurcation, dentinoma removal or S-shaped canal preparation [14].

Nowadays, studies comparing the effectiveness of bacterial elimination from root canals after chemo-mechanical manual and machine root canal preparation are performed. Such a study was conducted in 2011 and showed that both methods are not $100 \%$ effective in removing microorganisms. The method with manual instruments was slightly more effective in eliminating bacteria compared to the machine method using the ProTaper system [6].

However, considering the small differences and other advantages of the machine system, the method of root canal preparation should be selected individually, taking into account the size of the canal, shape of the root or other factors.

In 13 years, the popularity of thermal methods increased from 8,5\%[2] to $61,3 \%$, while the interest in single-cone obturation methods has decreased from $38,8 \%[2]$ to $11,7 \%$. Lateral condensation of cold gutta-percha has also decreased by 19,4 percentage points since 2008 [2]. It is worth noting the fact that doctors are not using sealants alone in 2021, which despite the European Society of Endodontics recommendations: "the canal filling should consist of a (semi) solid material in combination with a sealant, whose task is to fill the spaces between the (semi) solid material and the canal walls" [1] was used by $5.8 \%$ of the respondents in 2008 [2]. 
In 2014, an in vitro study was conducted to evaluate the tightness of root canal filling [5]. Three methods were compared: single-cone obturation, lateral gutta-percha condensation, hot gutta-percha. Based on the results, the following conclusions were made: the method of condensation of hot gutta-percha provides the highest tightness of root canal filling, the technique of condensation of hot gutta-percha provides the optimal gutta-percha - sealant relation, in each of the presented methods the highest risk of leakage is in the apical zone, 1-2 $\mathrm{mm}$ from the root apex, the hot gutta-percha condensation method enables tight filling of root canals of untypical, irregular shape

The question about the rinsing protocol met with a wide variety of answers. This is probably due to lack of standardization of root canal irrigation regimens [7,8,9]. This study showed that the most commonly used rinsing sequences are:

- $\quad$ sodium hypochlorite, citric acid or EDTA (27.9\%);

- sodium hypochlorite, citric acid or EDTA, sodium hypochlorite $(9.9 \%)$,

while root canal irrigation with sodium hypochlorite alone is preferred by $9.9 \%$ of the respondents. Despite the large discrepancy in responses, suggesting the need to develop a single effective and safe protocol, sodium hypochlorite, a compound that exhibits immediate antimicrobial activity [15], citric acid, and saline are listed among the most commonly used rinsing agents.

In 13 years, there has been an upgrade in dental practices. The popularity of apex locators, but also magnifiers, microscopes and ultrasound have increased. Endometers are used in $99.1 \%$ of dental practices, which probably contributed to the fact that as many as $84.7 \%$ of respondents measure the working length of the canals using only electronic methods. In 2008 only $61 \%$ of respondents confirmed the use of endometer [2].

It is noteworthy that in 2008 microscope was used by $8,2 \%$ of dentists [2]. In 2021 it was used by $70 \%$ of dentists, which is increasingly proving that microscope is an indispensable tool in the endodontic arsenal of the 21 st century [16].

In endodontics, the microscope is essential for: diagnosis, locating hidden canals, management of calcified canals, perforation repair, retrieval of broken files and final examination of the canal preparation[17]. According to studies, microscope provide greater visibility of the root canal anatomy, so procedural errors can be reduced [17].

The use of magnifying tools has expanded the range of procedures performed in the dental office and increased the percentage of successful procedures. Perhaps it is the increased popularity of loupes and microscopes that has contributed to the more frequent removal of broken instruments, unblocking of obliterated canals or treatment of traumatized teeth in Polish dental offices.

Interest in ultrasound has also increased - from $19,5 \%$ in 2008 [2] to $84,7 \%$ in 2021. It is said that ultrasound tools have moved from luxury to necessity status [18]. Ultrasonic activation of irrigants is a clinically proven and effective way to increase flushing efficiency [19]. It produces at least 2 effects: cavitation, defined as the formation of thousands of small bubbles that quickly collapse, producing a "shock wave" - that removes biofilm, and acoustic jet, which produces shear forces that help pull debris out of the canals. In addition, ultrasound is also used to remove and thicken gutta-percha, vibrate perforation repair materials, and surgically prepare the root apex. 
There are now an increasing number of procedures in which ultrasound is used during restorations - marginal finishing, interproximal restorations and small lingual restorations. Ultrasound is also a valuable tool for treating calcified and hard-to-find canals [18].

It is worth mentioned that dental studies are characterized by an extensive program that requires significant effort and a predisposition to clinical work with patients. The anatomical variety of root canals, the need to provide adequate patient care, and the lack of self-confidence among students and dentists have prompted many of them to consider endodontics to be an extremely difficult and stressful discipline not only for students $[20,21,22]$.

\section{Conclusions:}

This year's study is filled with optimism. Comparing the results to those of 2008, it can be unequivocally admitted that Polish endodontic dentistry has made several steps forward - the present X-ray equipment in almost every dental practice, the rubber dam used by $80 \%$ of dentists and the performance of the recommended three radiographs by almost $3 / 4$ of the respondents. Apart from that, less effective methods of root canal filling have been abandoned in favour of the thermal method, which ensures an optimal gutta-percha-sealant relation. In Polish dental offices, microscopes and ultrasounds have also become common, while the endometer and electronic measurement have replaced less precise radiographs. Attention should also be paid to more frequently performed procedures, such as root resection or removal of broken instruments, which 13 years ago were performed by less than $5 \%$ of respondents.

The only concern and surprise is the continuing popularity of the traditional method of root canal preparation, which despite its many disadvantages is still one of the most commonly used. The variety of root canal rinsing schemes used by the interviewed dentists is also questionable.

The conducted survey indicates the need to conduct research comparing the effectiveness of root canal preparation methods and to standardize the rinsing protocol.

\section{References:}

1. European Society of Endodontology. Quality guidelines for endodontic treatment: consensus report of the European Society of Endontology. Int. Endod. J. 2006;39:921-930.

2. Olczak K, Pawlicka H. Methods and agents used by dental practitioners during endodontic treatment - survey study. Czas. Stomol. 2008;61(12):851-857.

3. Kosińska K, Sobecka M. Radiological aspects in endodontic treatment. Nowa Stomatol. 2013;3:128-129.

4. Bagińska J, Wilczko M, Kudaszewicz B. Methods of assessment of the accuracy of electronic apex locators. A review of the literature. Nowa Stomatol. 2013;4:201.

5. Gołąbek H, Dominiak K, Mielczarek A. An assessment of the apical microleakage of root canal fillings - a comparative in vitro study. Nowa Stomatol. 2014;1:29.

6. Postek-Stefańska L, Mazur T, Wysoczańska-Jankowicz I. The Comparison of the Effectiveness of Bacterial Elimination from Root Canals after Chemomechanical Preparation with Hand and Rotary Instruments. Dent. Med. Probl. 2011;48(4):496-504. 
7. Wilkoński W, Jamróz-Wilkońska L. Protocol for irrigating root canals according to indications of Research Department of Polish Endodontic Society. Mag. Stomatol. 2013;246(1):92-94.

8. Olczak K. Ostateczne płukanie kanałów korzeniowych po ich opracowaniu - kontrowersje wokół tak zwanej warstwy mazistej. Forum Stomatol. Prakt. 2014:22:68-72.

9. Wilkoński W. The effects of alternate irrigation of root canals with chelating agents and sodium hypochlorite on the effectiveness of smear layer removal. Adv Clin Exp Med. 2020;29(2):209-213. https://doi.org/10.17219/acem/112603.

10. Krupiński J. Principles and practice of endodontic treatments. The technique of the root canal preparation by the hand instruments. Porad. Stomatol. 2003;2:6.

11. ADA Publishing Division. For the Dental Patient: Dental radiographs: Benefits and safety. JADA. 2011;142(9):1101.

12. Bieżanek T, Bachanek T. Comparison of root canal system disinfection effectiveness with and without rubber dam use. Pomeranian J. Life Sci. 2015;61(1):76.

13. Bhuva B, Chong B.S, Patel S. Rubber dam in clinical practice. Endo. 2008;2(2):131-141.

14. Kacprzak M, Drabarczyk-Nasińska M. Modern endodontic treatment - methods of canal root preparation. Nowa Stomatol. 2001;3:8-10.

15. Prada I. Update of the therapeutic planning of irrigation and intracanal medication in root canal treatment. A literature review. Oral Surg Oral Med Oral Pathol Oral Radiol. 2019;106(2):84-89. https://doi.org/10.4317/jced.55560.

16. Monea M, Hantoiu T, Stoica A, Sita D, Sitaru A.The Impact Of Operating Microscope On The Outcome Of Endodontic Treatment Performed By Postgraduate Students. Eur. Sci. J. 2015;11(27):305-311.

17. Kim S, Baek S. The microscope and endodontics. Dent. Clin. North Am. 2004;48(1):11-8. https://doi.org/10.1016/j.cden.2003.12.001.

18. Glassman G, Kratchman S. Ultrasonics in endodontics: luxury or necessity? Dent. Today. 2011;30(9):114, 116-9.

19. Paragliola R. Franco V, Fabiani C, Mazzoni A, NATO F, Tay F.R, Breschi L. Grandini S. Final Rinse Optimization: Influence of Different Agitation Protocols. J Endod. 2010;36(2): 282-285. https://doi.org/10.1016/j.joen.2009.10.004.

20. Mocny-Pachońska K, Doniec RJ, Wójcik S, Sieciński S, Piaseczna NJ, Duraj KM, Tkacz EJ. Evaluation of the Most Stressful Dental Treatment Procedures of Conservative Dentistry among Polish Dental Students. Int. J. Environ. Res. Public Health. 2021;18(9):4448. https://doi.org/10.3390/ijerph18094448.

21. Mocny-Pachońska K, Doniec R, Trzcionka A, Pachoński M, Piaseczna N, Sieciński S, Osadcha O, Łanowy P, Tanasiewicz M. Evaluating the stress-response of dental students to the dental school environment. PeerJ. 2020;8:e898. https://doi.org/10.7717/peerj.8981.

22. Mocny-Pachońska K, Trzcionka A, Doniec RJ, Sieciński S, Tanasiewicz M. The Influence of Gender and Year of Study on Stress Levels and Coping Strategies among Polish Dental. Med. 2020;56(10):531. https://doi.org/10.3390/medicina56100531. 